\title{
Effect of glucagon on infants and children with atrioventricular heart block $^{1}$
}

\author{
Roger A. Hurwitz \\ From Department of Pediatrics, Division of Cardiology, Indiana University Medical School, Indiana, U.S.A.
}

Glucagon was administered to 13 infants and children with advanced atrioventricular block. The drug produced a positive response in 12 children when given intravenously in a dose of $0.02-0.05 \mathrm{mg} / \mathrm{kg}$. Ventricular rate rose approximately 20 per cent. Cardiac output rose in each of the 4 patients so tested. Onset of action was within 3 minutes. Though the duration of response lasted nearly 20 minutes, any significant effect had usually disappeared 15 minutes after injection of the drug. No severe side effects or adverse arrhythmias were encountered in this study.

Glucagon has been shown to possess positive chronotropic and inotropic responses in subjects with either normal or abnormal cardiovascular systems (Parmley and Sonnenblick, 197I; Linhart et al., 1968; Glick et al., 1968; Parmley, Glick, and Sonnenblick, 1968; Nord, Fontanes, and Williams, 1970; Williams et al., 1969). Despite its recognized chronotropism, glucagon has been incompletely studied in subjects with advanced atrioventricular heart block. Dogs with acute and chronic acquired atrioventricular heart block showed a positive response after glucagon administration (Hurwitz, I97I). Adults with acquired block and fixed-rate pacemakers responded to intravenous injections of glucagon with an increase in cardiac output (Ashley et al., 1970). Recent studies in adults with chronic atrioventricular heart block have been contradictory (Gavrilescu et al., I97I; Nishimura, Fortner, and Williams, 1972).

The purpose of this study is to present the initial cardiovascular data obtained after administration of glucagon to infants and children with advanced atrioventricular heart block, either congenital, postoperative, or metabolic in origin.

\section{Patients and methods}

Glucagon was administered to 13 patients with cardiac arrhythmias, predominantly atrioventricular dissociation and bradycardia (Fig. I). Their ages ranged from 2 days to 16 years (Table). In the II patients in whom complete atrioventricular heart block was the dominant rhythm, an attempt was made to distinguish between a

Received I4 June 1973.

1 Supported by a grant from the Riley Memorial Association. junctional and an idioventricular pacemaker. The latter was considered present when there was atrioventricular dissociation, bradycardia, and a slurred $Q R S$ complex of prolonged duration. By these criteria, 5 patients had complete atrioventricular heart block with pacing stimulus probably distal to junctional tissue, and 6 had complete block with junctional pacemaking. One patient had a I:I atrial-ventricular response and junctional rhythm, and one had second-degree block with a 2: I atrial-ventricular response. Arrhythmia was surgically acquired in 4 cases and was congenital in 8 . Case 12 had a severe metabolic disturbance with acidosis and congestive failure probably caused by sepsis.

Before glucagon administration, informed consent was obtained by discussing the use of the drug with the family of each patient. It was explained that glucagon had been used to treat hypoglycaemia in many infants and children as well as being used as a cardiotonic drug for many adult patients. The cardiac effects of glucagon were to be studied to determine possible effectiveness of the drug in symptomatic atrioventricular heart block. If effective it could then be administered as a temporary agent during critical periods, such as pacemaker implantation. The research protocol was submitted to and approved by the Committee for Human Research at Indiana University Medical School before the project was begun.

The effect of glucagon was studied during the course of diagnostic cardiac catheterization in 6 patients. Right and left heart catheterization was routinely performed. Older children were sedated with a mixture of pethidine hydrochloride I mg/kg, chlorpromazine $0.25 \mathrm{mg} / \mathrm{kg}$, and promethazine hydrochloride $0.25 \mathrm{mg} / \mathrm{kg}$. Haemodynamic variables were recorded at rest and after intravenous administration of glucagon, 0.02 to $0.05 \mathrm{mg} / \mathrm{kg}$ given over 30 seconds. Pressures were measured by Statham P23dB transducers. Cardiac output was obtained by injecting indocyanine-green dye into the pul- 


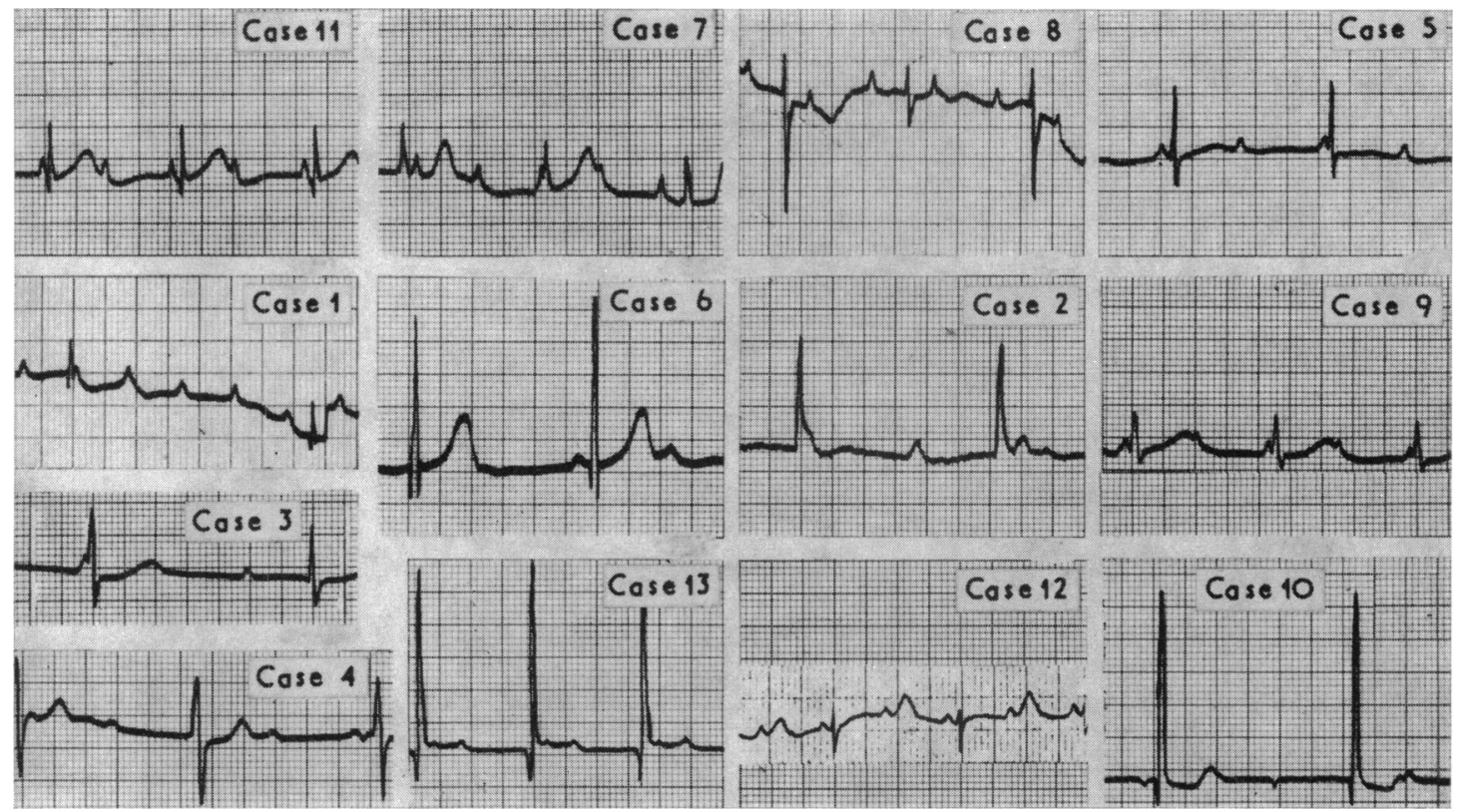

FIG. I Representative electrocardiographic tracings from all patients.

TABLE Data from all infants and children treated with glucagon

\begin{tabular}{|c|c|c|c|c|c|c|c|c|c|c|c|c|c|}
\hline $\begin{array}{l}\text { Case } \\
\text { No. }\end{array}$ & Age & $\begin{array}{l}\text { Weight } \\
(\mathrm{kg})\end{array}$ & Rhythm & Aetiology & $\begin{array}{l}\text { Glucag } \\
\text { Dose }\end{array}$ & $\begin{array}{l}\text { gon } \\
\text { Route }\end{array}$ & $\begin{array}{l}\text { Ventr } \\
\text { Rest }\end{array}$ & $\begin{array}{l}\text { icular ra } \\
\text { Iso- } \\
\text { prena- } \\
\text { line }\end{array}$ & $\begin{array}{l}\text { ate/min } \\
\text { Rest }\end{array}$ & $\begin{array}{l}\text { Glu- } \\
\text { cagon }\end{array}$ & $\begin{array}{l}\text { Cardid } \\
\text { (l./min } \\
\text { Rest }\end{array}$ & $\begin{array}{l}\text { ac output } \\
\text { Glu- } \\
\text { cagon }\end{array}$ & $\begin{array}{l}\text { Blood pressure } \\
\text { Rest } \begin{array}{c}\text { Glu- } \\
\text { cagon }\end{array}\end{array}$ \\
\hline I & II mth & 7 & $3^{\circ} \mathrm{AVB}$ & Congenital & 0.02 & IV & 34 & $4 I$ & 36 & 42 & 0.8 & $\mathbf{I} \cdot \mathbf{I}$ & $112 / 46108 / 52$ \\
\hline 2 & $16 \mathrm{yr}$ & 113 & $3^{\circ} \mathrm{AVB}$ & " & 0.02 & IV & 44 & 56 & 42 & 48 & $5 \cdot 7$ & $6 \cdot 1$ & $128 / 64126 / 70$ \\
\hline 3 & $7 \mathrm{yr}$ & 24 & $3^{\circ} \mathrm{AVB}$ & & 0.04 & IV & & & 43 & 52 & 4.0 & $4 \cdot 7$ & $96 / 46100 / 50$ \\
\hline 4 & $8 \mathrm{yr}$ & 2 I & $3^{\circ} \mathrm{AVB}$ & Acquired & 0.05 & IV & & & 54 & 58 & & & $109 / 64130 / 86$ \\
\hline 5 & $3 \mathrm{mth}$ & 8 & $3^{\circ} \mathrm{AVB}$ & , & 0.04 & IM & & & 60 & 60 & & & \\
\hline 6 & IO $\mathrm{yr}$ & 24 & $3^{\circ} \mathrm{AVB}$ & Congenital & 0.04 & IV & 64 & 78 & 61 & 68 & $5 \cdot 5$ & $6 \cdot 6$ & $118 / 76$ I $14 / 78$ \\
\hline 7 & I yr & 7 & $3^{\circ} \mathrm{AVB}$ & $"$ & 0.05 & IV & 64 & 68 & 65 & 69 & & & $102 / 60104 / 66$ \\
\hline 8 & Io dy & 3 & 2-3 ${ }^{\circ}$ VVB & " & 0.05 & IV & & & 66 & 80 & & & $62 / 38 \quad 70 / 38$ \\
\hline 9 & $8 \mathrm{yr}$ & 20 & $3^{\circ} \mathrm{AVB}$ & Acquired & 0.05 & IV & & & 68 & 80 & & & \\
\hline 10 & $6 \mathrm{yr}$ & I8 & $3^{\circ} \mathrm{AVB}$ & Congenital & 0.05 & IV & & & 70 & 98 & & & I I9/64 I30/86 \\
\hline II & $\begin{array}{l}2 d y \\
3 d y\end{array}$ & 3 & $3^{\circ} \mathrm{AVB}$ & " & $\begin{array}{l}0.05 \\
0.05\end{array}$ & $\begin{array}{l}\text { IM } \\
\text { IV }\end{array}$ & & & $\begin{array}{l}71 \\
70\end{array}$ & $\begin{array}{l}73 \\
80\end{array}$ & & & \\
\hline 12 & $3 \mathrm{dy}$ & 3 & $\begin{array}{c}2^{\circ} \mathrm{AVB} \\
2: 1\end{array}$ & Metabolic & 0.05 & IV & & & 76 & 87 & & & \\
\hline 13 & $3 \mathrm{yr}$ & 12 & $\begin{array}{c}\text { Junc } \\
I: I\end{array}$ & Acquired & 0.05 & IV & & & 84 & 95 & & & $120 / ? \mathrm{I} 50 /$ ? \\
\hline
\end{tabular}

$\mathrm{AVB}=$ atrioventricular block; Junc $=$ junctional $;$ Dose $=$ dose in $\mathrm{mg} / \mathrm{kg}$.

monary artery and sampling from the descending aorta. Duplicate measurements were performed; average values are given in the Table. Isoprenaline, 0.05 to $0.10 \mu \mathrm{g} / \mathrm{kg}$ per minute, was administered to 4 patients and the response was measured after 4 minutes of infusion. In all cases at least 20 minutes elapsed between isoprena- line and glucagon infusion. Data were recorded on an Electronics for Medicine SGM recorder.

In 7 patients glucagon was administered at the bedside either intramuscularly or as an intravenous bolus in doses of 0.04 to $0.05 \mathrm{mg} / \mathrm{kg}$. Heart rates were recorded on a Hewlett-Packard I5 IA electrocardiograph and moni- 


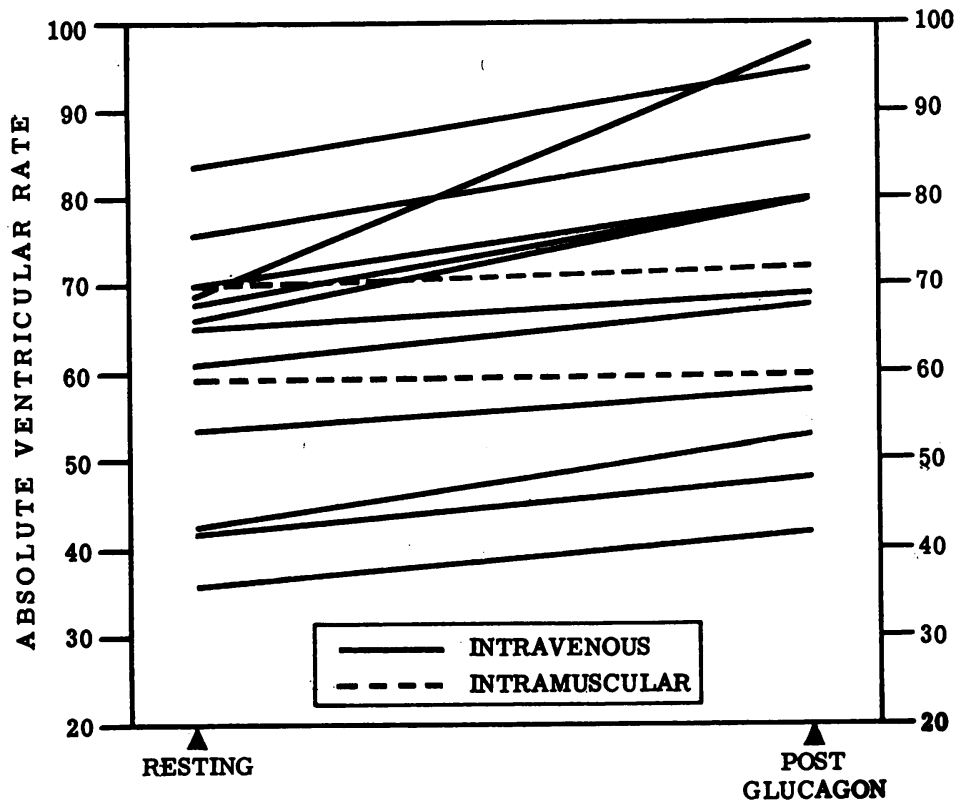

FI G. 2 Ventricular rate at rest and after parenteral administration of glucagon in 13 patients so tested. Post-glucagon rates are maximal. Case II was tested twice (once intravenously and once intramuscularly).

tored on a Hewlett-Packard 7803A oscilloscope. Blood glucose and potassium values were determined before and Io minutes after injection of glucagon in 3 patients.

The difference in ventricular rate before and after glucagon was analysed by Student's t-test for paired data. The time course for intravenous glucagon response was obtained by polynomial regression analysis.

\section{Results}

The ventricular rate increased in 12 patients after glucagon administration (Fig. 2). Only Case 5, given glucagon intramuscularly, showed no response. In patients with complete atrioventricular heart block the mean resting ventricular rate was 58 beats a minute. The mean maximal ventricular rate after parenteral glucagon was 67 beats a minute. The mean difference was statistically significant $(\mathrm{P}<0.001)$. The onset of action was early in all cases. The maximal effect was frequently at 2 to 5 minutes. Though this chronotropic response persisted beyond 15 minutes in a few cases, the significant effect generally lasted Io to 15 minutes (Fig. 3). Isoprenaline infusion increased the ventricular rate to similar or slightly higher levels than did glucagon in 4 patients. However, in 2 patients isoprenaline produced changing rhythms, including bigeminy and multiple ventricular foci.

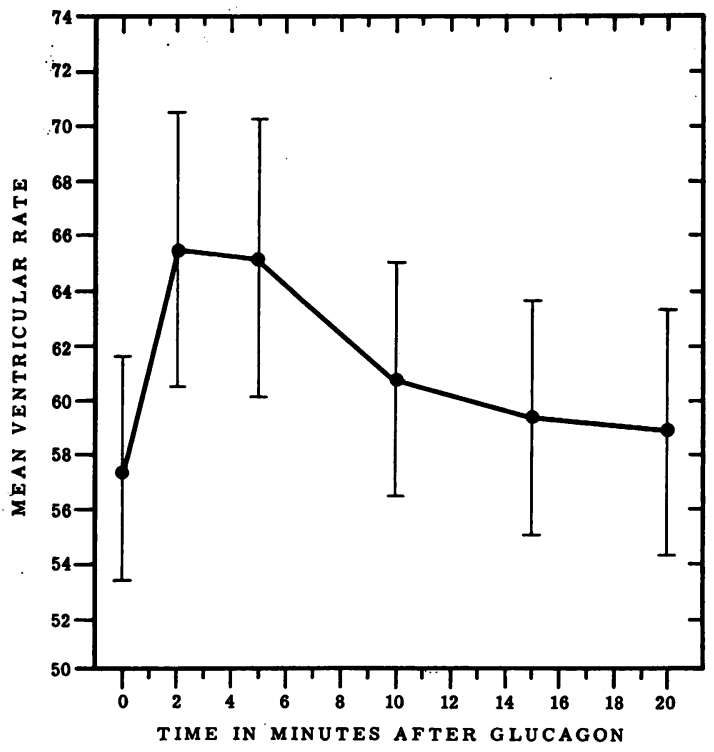

FIG. 3 Time course for glucagon response expressed as the mean ventricular rate in beats a minute after intravenous glucagon in 12 patients. Case 5, who received intramuscular glucagon, was excluded from this figure. The standard error of the mean is bracketed. 
Cardiac output increased after glucagon in the 4 patients so studied. However, in Case 2 it rose only 7 per cent. This patient's stroke volume decreased slightly, as did that in Case 3. The stroke volume rose in Cases $I$ and 6 . After glucagon administration, systolic blood pressure increased from 120 to 150 $\mathrm{mmHg}$ in Case 13 , in borderline congestive heart failure and with low cardiac output after open-heart surgery. Blood pressure also rose in Case ro, but was unchanged in the other patients. Rhythm remained constant in all patients except Case 13, in whom rhythm transiently changed to first-degree atrioventricular heart block for 15 minutes after drug infusion. Ventricular rate and cardiac output fell in only one patient, Case 3. This occurred 15 minutes after infusion of glucagon, which had earlier increased rate and output. The fall accompanied nausea and gagging.

Blood glucose values, determined in 3 patients, rose by 20 to $40 \mathrm{mg} / \mathrm{roO} \mathrm{ml}$. Potassium levels remained within $0.3 \mathrm{mEq} / \mathrm{l}$. of the control level. Case 3 was the only patient who had side effects.

\section{Discussion}

Heart block accompanied by bradycardia is often life threatening to an infant or child, especially when it arises at the time of corrective operation or is associated with additional malformations of the heart (Lillehei et al., 1963; Nakamura and Nadas, 1964). The low resting ventricular rate and the inability of the heart to respond to stress with tachycardia may produce an insufficient cardiac output, myocardial hypoxia, and a more devastating arrhythmia such as ventricular fibrillation. Since glucagon has been shown to possess cardiotonic properties and has been safely employed for many years in the treatment of symptomatic hypoglycaemia in infancy, it seemed appropriate to evaluate the drug in paediatric patients with bradyarrhythmias.

Of 13 patients in this study, I I had complete atrioventricular heart block. His bundle recording to determine the exact site of pacemaking impulse was not employed, though the pacemaking origin appeared to be idioventricular in 5 patients. Resting ventricular rates in some cases were higher than those commonly seen with complete atrioventricular heart block; however, these patients were infants or children in the immediate postoperative period. This type of patient usually has a ventricular rate well over 100 beats a minute.

Data accumulated in the present study indicate a positive chronotropic response to single bolus intravenous injections of glucagon. The 20 per cent increase in maximal ventricular rate is similar to the rate increment seen both in normal adults and in those with a compromised cardiovascular system (Parmley and Sonnenblick, I97 I; Linhart et al., 1968). The adrenergic agent isoprenaline was administered to 4 patients and resulted in rate increases of the same magnitude as those seen with glucagon. However, isoprenaline resulted in further worrisome arrhythmias in 2 patients. The response to glucagon was almost immediate, with peak effects between 3 and ro minutes. Though the rate was modestly raised for $\mathbf{2 0}$ minutes in a few cases, the major effect was dissipated within 15 minutes. A succeeding dose of glucagon was administered twice with only an 8 per cent further increment in rate after initial increases of 17 and 22 per cent. Cardiac output rose in the 4 patients so tested, but only slightly in one (Case 2); however, this extremely obese youngster received only $0.02 \mathrm{mk} / \mathrm{kg}$ glucagon. The average increment in cardiac output was similar to previously reported data in adults without heart block (Parmley and Sonnenblick, 1971; Linhart et al., 1968). Interestingly, results from the two studies of glucagon in adults with atrioventricular heart block have been contradictory. In one (Nishimura et al., 1972) glucagon administration did not significantly affect the rate of the spontaneous pacemaker. On the other hand, Gavrilescu et al. (1971) found that glucagon increased the ventricular rate in adults with chronic atrioventricular heart block.

The mechanism by which glucagon produces positive chronotropism has not been delineated. The drug has increased ventricular automaticity in vitro and in vivo (Stewart, Myerburg, and Hoffman, 1969; Wilkerson, Pruett, and Woods, 197I; Lucchesi, I968). Glucagon has also been shown to reverse quinidine-induced decreases in action potential. The augmented automaticity was not catecholamine dependent, since propranolol did not block glucagon's action (Wilkerson et al., 197I).

In this study, patients with an apparent pacing site in junctional tissues and those whose pacemaking site appeared to be distal to the atrioventricular node had similar responses to glucagon. Furthermore, those with congenital atrioventricular block and those with surgically acquired block responded similarly. Infants and older children had similar responses to glucagon administered according to weight. Unfortunately, clinical improvement could not be evaluated in these patients, since for the most part they received only single bolus injections of the drug.

The usual dosage of glucagon in this study was that commonly employed (Parmley and Sonnenblick, 197I; Williams et al., 1969). In 2 patients (Cases I and 2) a much lower dose produced a positive response. No significant change in ventric- 
ular rate was observed after intramuscular glucagon injection in 2 patients. One of these (Case I I), tested intravenously, had a definite rise in rate. Though this might imply that intramuscular administration is ineffective, larger intramuscular doses of glucagon might achieve a positive response. Tachyphylaxis, suggested by the response seen here in 2 patients, may also limit the drug's effectiveness. However, constant infusion of glucagon has resulted in augmentation of cardiac output in low output states (Vander Ark and Reynolds, 1970).

No significant side effects were encountered during or after administration of glucagon to infants and children in a dose of $0.05 \mathrm{mk} / \mathrm{kg}$. No prolonged fall in cardiac rate, cardiac output, or systemic blood pressure was experienced. No new arrhythmias were seen. Nausea and vomiting, commonly encountered in adults given glucagon, were transiently encountered in only I patient (Nord et al., 1970; Williams et al., 1969; Vander Ark and Reynolds, 1970).

Though glucagon's onset of action is almost immediate, the transient pharmacological effect suggests limited clinical usefulness for the drug. Glucagon may, however, serve as a valuable adjunct in temporary treatment of symptomatic bradyarrhythmias. It may have special merit in the treatment of digitalis or propranolol toxicity resulting in atrioventricular heart block, especially during insertion of a cardiac pacemaker.

The author thanks Dr. Pao-Lo Yu for the statistical analysis.

\section{References}

Ashley, W. W., Kaminsky, D. M., Lipski, J. I., Weisenseel, A. C., Jr., Donoso, E., and Friedberg, C. K. (1970). Hemodynamic effects of glucagon in patients with fixedrate pacemakers (abstract). American fournal of Cardiology, $25,82$.

Gavrilescu, S., Streian, C., Pop, T., and Vicas, E. (1971). Hemodynamic effect of glucagon in patients with chronic complete heart block. Cor et Vasa, 13, 85.
Glick, G., Parmley, W. W., Wechsler, A. S., and Sonnenblick, E. H. (I968). Glucagon: its enhancement of cardiac performance in the cat and dog and persistence of its inotropic action despite beta-receptor blockade with propranolol. Circulation Research, 22, 789.

Hurwitz, R. A. (1971). Effect of glucagon on dogs with acute and chronic heart block. American Heart fournal, 81, 644.

Lillehei, C. W., Sellers, R. D., Bonnabeau, R. C., and Eliot, R. S. (1963). Chronic postsurgical complete heart block. fournal of Thoracic and Cardiovascular Surgery, 46, 436.

Linhart, J. W., Barold, S. S., Cohen, L. S., Hildner, F. J., and Samet, P. (1968). Cardiovascular effects of glucagon in man. American fournal of Cardiology, 22, 706.

Lucchesi, B. R. (1968). Cardiac actions of glucagon. Circulation Research, 22, 777.

Nakamura, F. F., and Nadas, A. S. (1964). Complete heart block in infants and children. New England fournal of Medicine, 270, I26I.

Nishimura, A., Fortner, R. B., and Williams, J. F., Jr. (1972). Effect of glucagon on automaticity, threshold for stimulation, and atrioventricular conduction in patients with impaired impulse formation or conduction. American Heart fournal, 84, 359.

Nord, H. J., Fontanes, A. L., and Williams, J. F., Jr. (1970). Treatment of congestive heart failure with glucagon. Annals of Internal Medicine, 72, 649.

Parmley, W. W., Glick, G., and Sonnenblick, E. H. (1968). Cardiovascular effects of glucagon in man. New England fournal of Medicine, 279, 12.

Parmley, W. W., and Sonnenblick, E. H. (1971). Glucagon: a new agent in cardiac therapy. American fournal of Cardiology, $27,298$.

Stewart, J. W., Myerburg, R. J., and Hoffman, B. F. (1969). The effect of glucagon on quinidine-induced changes in Purkinje fibers. Circulation, Suppl. 39, III, 196.

Vander Ark, C. R., and Reynolds, E. W., Jr. (1970). Clinical evaluation of glucagon by continuous infusion in the treatment of low cardiac output states. American Heart fournal, 79, 481 .

Wilkerson, R. D., Pruett, J. K., and Woods, E. F. (1971). Glucagon-enhanced ventricular automaticity in dogs. Circulation Research, 29, 616.

Williams, J. F., Jr., Childress, R. H., Chip, J. N., and Border, J. F. (1969). Hemodynamic effects of glucagon in patients with heart disease, Circulation, 39, 38.

Requests for reprints to Dr. Roger A. Hurwitz, Section of Pediatric Cardiology, James Whitcomb Riley Hospital for Children, I roo West Michigan Street, Indianapolis, Indiana 46202 , U.S.A. 